\title{
An Integrated Model for Managing Organizational Change
}

\author{
Khaled A. Bubshait, Mohammed A. Burney \& Iftikhar A. NadeEm \\ Associate Professors \\ Department of Accounting and Management Information Systems \\ King Fahd University of Petroleum and Minerals \\ Dhahran - Saudi Arabia
}

(Received 5.6.1417H, and Accepted 18.2.1418H)

\begin{abstract}
Changes in organizations, both planned and unplanned, respond to forces from within and outside organizations. Management of change requires vigilance because change affects people's work, powers, and interactions. According to the existing models of change, people either accept or resist change. However, in order to maintain equilibrium, people influence the process of change. So, they may not only resist or accept change, but may also deviate the desired out omes. To concede this fact, a more effective framework has been developed and presented here to better understand the change process. According to this framework, the key to successful change is to diagnose the organization with its people as an integral part of it, map a comprehensive action plan, and be prepared to intervene repeatedly until the desired results are achieved.
\end{abstract}

\section{Introduction}

The globalization of markets, increasingly competitive business environment and rapid technological growth, mandate organizations to cope with new sets of variables and conditions in order to survive and maintain competitiveness. The ideal organization bears the label of a cozy fit of external opportunities, organization strategies, internal structures, systems, and cultures. The real test of executive leadership then is in maintaining this alignment in the face of changing competitive conditions. Organizations need to introduce planned changes in an effort to realign the mselves from time to time. The objectives of these changes can be improvement of product quality, simplification and speeding up of processes, development of new products or services, and reduction of production costs, or enhancement of the quality of life at work. 
In a recent survey conducted by the American Management Association, managing change emerged as the most common problem facing organizations today. The survey asked corporate managers to identify the biggest problem they face in today's business environment [1:14]. While according to another survey of 1,450 managers in twelve global organizations, nearly 60 percent of the respondents said their competitive environment was in the midst of transformation [1:15].

However, the task of managing change is not a bed of roses. Few managers possess the required operating skills to plan and implement change effectively. Many managers react to external demands with little conscious management of change and with little awareness that change is a continuous process. In the area of planned change managers are surprisingly inept, and too often failures are explained away as resistance to change. According to a Fortune 500 executive survey [20:34], only half of the executives described their recent change efforts as successful. Employee resistance to change was cited by 76 percent of the respondents as the major derailing factor. For that reason, organizational change has been a recent topic of concern for management theorists as well as practitioners. While the goals could be well-defined, usually the change process is - like a surgery - very much subjective and unpredictable.

\section{Need for Change}

A fundamental aspect of an organization's task is to achieve its goals, which can often be expressed in terms of product/service performance within the circumstances or constraints within which it operates and which prevent goal realization [19:32]. As organizations are open systems, external factors ( economic, market, technological, legal, and political situations), and internal factors (human resources, administrative structures, products/services, productivity, and organizational culture) hinder or frustrate the management in its implementation of the organizational goals. There is a continuous process of minor alignments going on that are induced by those external and internal constraints. These responsive, unplanned changes, usually do not create such shock waves which can impact the organization in a significant way. A simple example is the seasonal adjustments of production levels in a factory.

However, in order to cope with pressures built upon by one or several of the above factors and in an attempt to meet its objectives, a change of state in the organization's structure and/or functioning may become necessary from time to time. An organization may resign to strategic shifts such as alliances, mergers, acquisitions, divestitures, consolidations, etc.; or, it may adopt new business concepts and productivity improvement techniques to boost its operational efficiency such as just-intime, computer integrated manufacturing, material requirements planning, total quality management, and business process reengineering. Figure (1) illustrates the emergence of change induced by the dynamics of the external and internal forces. 


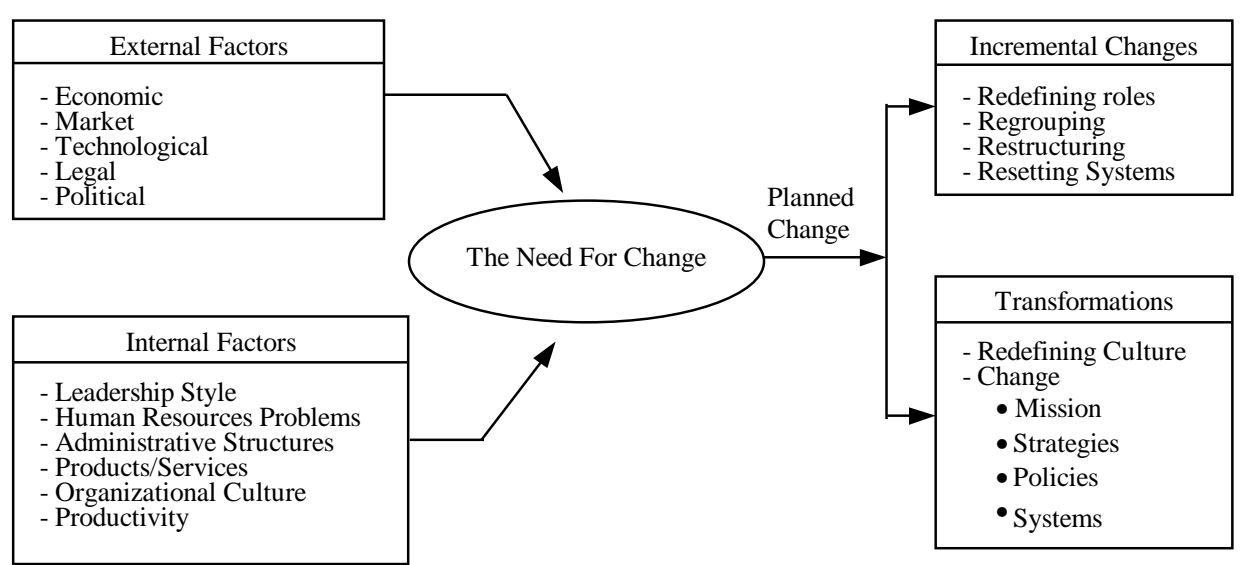

Fig. (1) The Need for Change

Planned change can be of two kinds: incremental change or complete transformations [2:14-15]. Incremental change becomes necessary from time to time in all organizations if they are to adapt to changing circumstances. An incremental change can involve a wide range of decisions and actions - redefining organization members' roles, creating new ones, regrouping activities, changing organization structures, modifying or abandoning existing systems and procedures, and introducing new ones.

The objective of the complete transformation is to transform the organization into a radically different form. It will always involve bringing changes in values, attitudes, and beliefs - the elements of corporate culture. Failure to bring about cultural change will doom to failure any attempt to achieve transformational change. A good example is the recent restructuring of the Bell System, Inc. which included complete changes in the mission, strategies, policies, structures, and systems of the corporation [18:321].

\section{Models of Change}

Much of the literature on the organizational change has been based on the social psychologist Kurt Lewin's [9:25] work. Lewin suggested that a planned change is composed of three steps: unfreezing the organization's existing culture by discontinuing current practices, attitudes and behaviors; creating cognitive recognition by teaching the work force the new concepts; and then refreezing the culture by reinforcing new practices, attitudes, and behaviors once the change was implemented.

We will briefly review here some other important models of change. Dunphy and Stace [3:20-21] have advanced a two-dimensional model of organizational change. The first dimension is the scale of change, and the second is the style of leadership required to bring about change. With regard to the former, the authors identified four types: fine tuning, incremental adjustment, modular transformation and corporate transformation. On the second dimension, the appropriate style of leadership is seen to range along a continuum from participative to autocratic. Dunphy and Stace then identified four 
types of change strategies: participative evolution, forced evolution, charismatic transformation, and coercive change.

Hardy and Redivo [5:30] have distinguished three types of planned changes an organization may want to bring about: behavioral, attitudinal, and conceptual or cultural. Behavioral change is the target of short term productivity improvement programs and is task oriented such as achieving a reduction in absenteeism rates by a remuneration plan. Attitudinal change stems from a difference in the awareness or understanding of a situation, which may or may not be directly reflected in measurements of behavior. A simple example might be improved service at a post office. Cultural change occurs in attempts to bring about system-wide change. An example might be a change from a hierarchical, authoritarian style of management to participative management.

A Systems Model of Change is based on the notion that any change has a cascading impact throughout an organization [12:192]. The three main components of a system model are inputs, target elements of change, and outputs. Inputs imply that all organizational changes as dictated by the external and internal factors cited above should be consistent with an organization's strategic mission and the resulting strategic plan. Target elements of change represent the components of an organization that may be changed. Output represents the desired end-result of a change.

Four other models worth mentioning here pertain to the implementation stage of an organizational change. Student [22:28] has discussed the human forces underlying planned change, and has identified key factors in implementing a successful change: influence, familiarity, testing, stress, and chance. Lippit [10] proposes a model that articulates phases of organizational crisis: shock, defense, retreat, acknowledgment, adaptation and change.

A transactional model, developed by Nutt [13:234], describes the interactions among five stages of planned change: formulation, concept development, detailing, evaluation, and installation. Within this framework one of four implementation tactics is employed: intervention, participation, persuasion, or edict. These tactics determine how much relative say-so the manager and support team have in shaping the change. The most effective implementation tactic was empirically found to be intervention, followed by participation and persuasion.

Another model developed by Rashford and Coghlan [16:17] draws analogy between human psychology and the organization. It postulates that change is an adaptive process and comprises four phases: denying, dodging, doing, and sustaining. These four phases of change occur progressively throughout the individuals, teams, groups, and organizations.

Strebel [20:29] has distinguished between strong and weak forces of change, strong and weak forces of resistance, and the balance between them. Either of four change paths are applicable if the forces of change are strong: resistance, renewal, revitalization, restructuring; similarly, four change paths are possible when the forces of change are weak: corporate realignment, cascading implementation, focused reengineering, and bottom-up experimentation. 
Kahn [6:494-95] has applied child development psychology to develop a change framework that focuses on how relationships between children and attachment figures (typically parents) facilitate or undermine children feeling secure. On the premises of this model, the change agent's task is to help organization members learn to cope with potentially threatening situations by giving encouragement, comfort, practical assistance, appropriate information, and access to essential material resources.

\section{Limitations of the Change Models}

Although the models of change have identified the importance of the human behavior in the change process, they have been conceptualized and treated in the context of either resistance or complete acceptance of the change sought (see, for example, [17:6]). Whereas the psychological models of change have generally focused on how the change takes place in an organization, they ignore the determinants of change and the interactions of the other prevailing forces which may influence a change process.

Nevertheless, the Systems Model of Change provides a useful, albeit mechanistic framework for understanding and affecting an organizational change. Figure ( 2 ) depicts the current Systems Model of Change. The model, however, suffers from three major flaws: it assumes that environment and the organizational strengths and weaknesses are the only factors to initiate a change; that the change will directly happen as predicted or it will fail; and, finally, that the change is a one-way act.

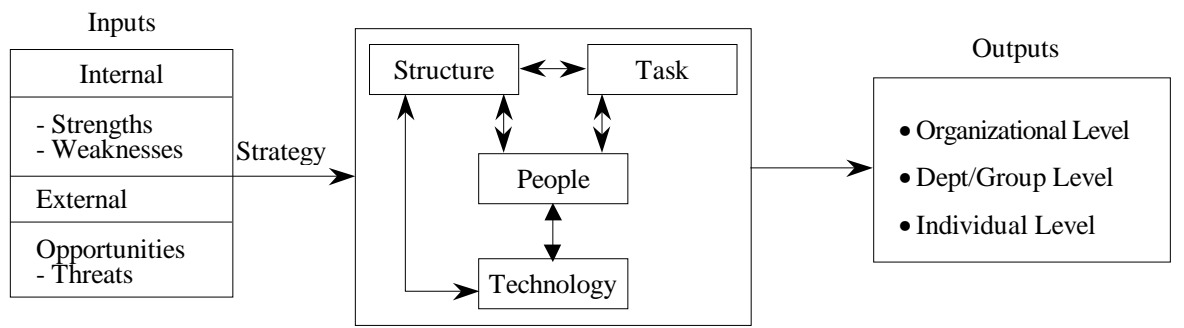

Fig. (2) Systems Model of change

\section{An Integrated Model for Change}

In reality, however, the organizations are not machines nor are they rational systems. The degree of acceptance of a change determines the willingness of people to provide relevant information about current operating problems, and what changes need to be made in the system of operation, if the organization's objectives are to be realized. People, in many aspects, welcome and even demand change. Consumers, for instance, are continually looking for new means and products for expressing their desires for change. Nevertheless, when an unsolicited change is imposed which affects their work styles, values, or relationships, they may not reject it, if only it would be in the form and to the extent that their individual characteristics, capabilities, and their vested interests are minimally disturbed. Organizational climate and the rewards systems will engrave their own marks on the process and outcomes of a change. 
There are several reasons why those projects which induce deliberate change fail or even do not go further than the blueprint sketches. On the part of the change agents cryptic vision, poor planning, lack of commitment, and improper timing of a change can only result in frustration and a waste of resources. Whereas, on the part of the organization, there can be many conflicting drives and forces to cope with during the course of change. These factors can hamper or deviate the desired objectives of a change initiative.

In 1982, Kodak responded to its lower revenues with a program of acquisitions designed to generate technical and financial synergy, while at the same time attempting to cut back its total work force and create a lean, divisionalized organization. However, the effort to derive synergies across diverse ventures in biotechnology, electronic imaging, data storage, batteries, and digital imaging resulted in an increase in central planning staff. Throughout five major restructuring efforts, the corporate overhead grew as other staff were being slashed. These exercises provided only a small bottom line improvement, but resulted in profound damages in employee morale and motivation due to vicious cycles of work force reductions [11:130].

Therefore, the resultant change may differ - even substantially — from what was originally planned and predicted. In other words, any planned change is the final product of complex interactions of not only the external and internal factors - as hypothesized by the Systems Model — but also of the individual goals, and psychological and behavioral characteristics of the organization members (both change agents and subjects).

We have found no published study that attempts to integrate the above human and organizational factors into the Systems Model of Change. Figure 3 depicts the proposed integrated model for a planned change. We have introduced several elements into the Systems Model:

1. Tension: this results when there is dissatisfaction about the current state in the organization. This situation stimulates an organization to head for a change. The change agent can utilize tension as an instrument to activate the people towards a desired state of equilibrium.

2. Power and Politics: successful organizational change involves more than the will and determination of a particular individual or group as some stakeholders may have to lose or risk their vested interests. And, thus, these persons can try to influence the process of change to their best interests, deviating the originally sought results.

3. Organizational Climate: this is defined as the current morale of the organization members such as trust in the management, stability of the day-to-day operations, and management's dependability and reliability from the members' perspective. This climate can play a vital role in shaping the final outcomes of a change process. 


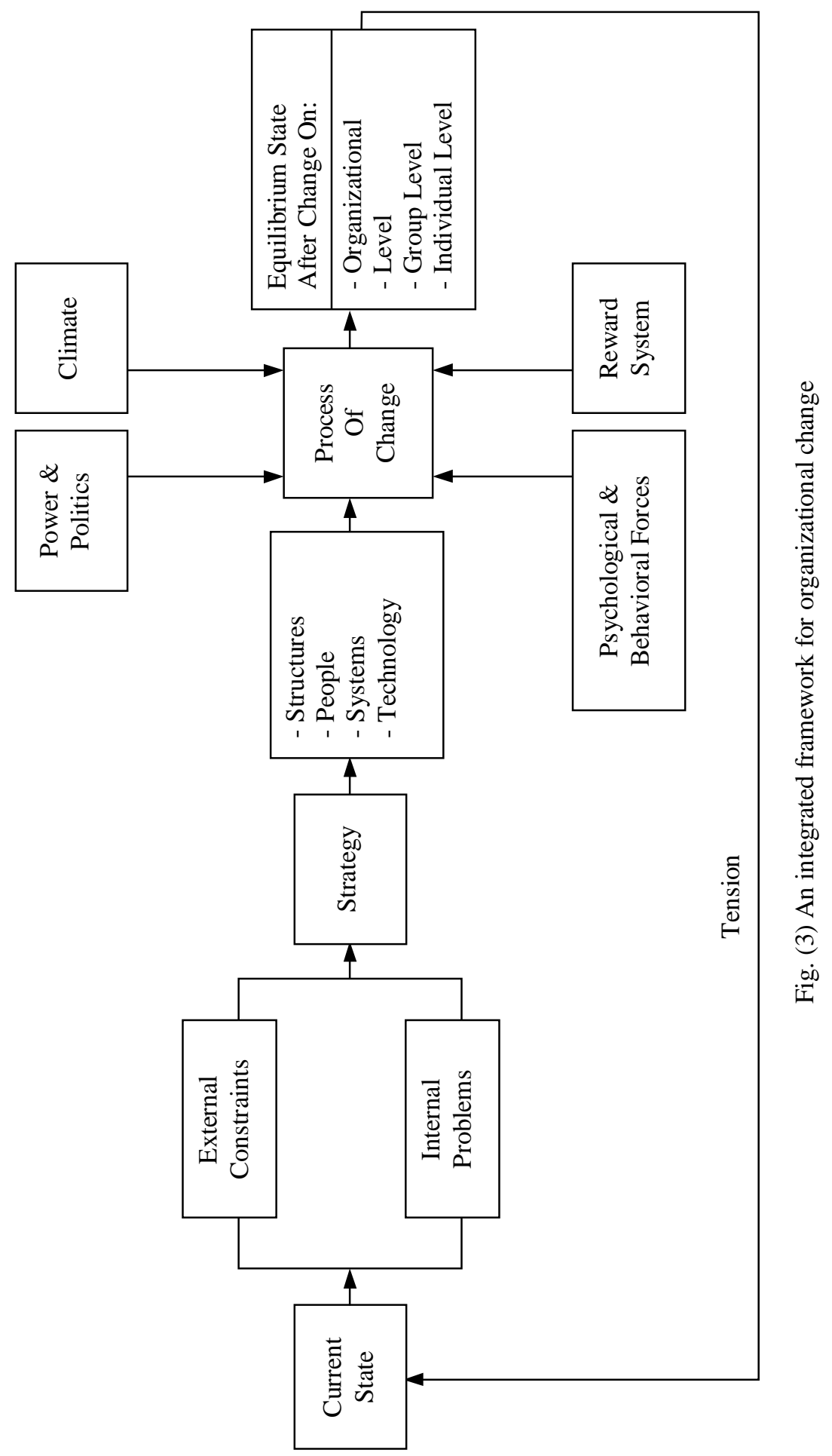




\section{Psychological and Behavioral Forces:}

- Management style, personality traits, beliefs, and cultural backgrounds of the individual change agents are key catalysts in a change process.

- Stress and strain are functional and useful to alert and/or speed up the change process, but excessive stress and strain imposed by change agents can alienate or antagonize the organization members.

- The diverse subcultures and social backgrounds of the individual organization members each contributes to shaping the organizational culture. These subcultures may act alongside the dominant culture in portraying the final shape of the change effort.

- Heuristic and acquired characteristics of the people (of both change agents or employees) may differ - sometimes considerably - in terms of drives, motives, mental sets, prejudices, knowledge, intelligence levels, and visions.

4. Rewards System: ensuring that people behave in a certain desired way is dependent on the ability to control the perceived or actual rewards of those persons concerned. If the rewards system is not consistent with the change objectives, it may hinder or distort the change outcomes.

These elements can leave subtle imprints on the outcomes of a change process. Therefore, before moving on with a change, they should be analyzed and critically assessed to get full understanding of the operational realities in an organization, and gain insights into the key barriers and hurdles to successfully implement a desired change.

The change process in this model calls for the involvement of the entire organization to buy in and commit to what is going to happen, and having the people understand their roles in implementation of the change. This model provides for not only the total acceptance or rejection of a change, but also a frizzled acceptance due to the interaction of human- and organization-related factors in shaping a change. It also establishes that the change is a dynamic process heading continuously from a tension state to an equilibrium state.

\section{Additional Concerns for Managing Change}

- Resistance to change: Any individual faced with a change in the organization in which he works may be resistant for a variety of reasons. People need a certain degree of stability or security, and change presents unknowns which cause anxiety [12:197]. In addition, a change that is imposed on individuals reduces their sense of autonomy or self-control. People typically develop patterns for coping with or managing the current structure and situation. Change means that they will have to find new ways of managing their own environments - ways that might not be as successful as those currently being used.

In addition, organization members who have power have a vested interest in the status quo and may resist change because it threatens that power [5:29, 13:230]. A climate of mistrust encourages secrecy, which begets deeper mistrust. Managers who trust their employees make the change process an open, honest, and participative affair. Intimidating changes on the job can cause employees to doubt their capabilities. 
Undue resistance can occur because changes are introduced in an insensitive manner or at an awkward time. Finally, individuals may resist change for ideological reasons; they may truly believe that the way things are done is better than the proposed change [8:113].

- Communication: Since what people do not know can hurt the organization, it is important to open a dialogue between management and people to preclude speculation $[4: 43,7: 84,21: 50]$. Knowledge prevents misinformation and disinformation and reduces the chance of a change failure. Moreover, improved quality of information used in key decisions overcomes the personal and political pressures resisting change [14:13], and helps the people to face the uncertainty brought by change as well as easing their adjustment to the new realities. Successful managers of long-term change encourage an atmosphere of learning in which employees test their hypothesis publicly rather than privately harboring prejudged conclusions [7:92].

- Organizational control: change disrupts the authority and reporting relationship structure undermining existing systems of management control, particularly those developed as part of formal organizational arrangements. As a result, during a change the organization may lose the capacity to effectively coordinate the work being done [4:42, 13:234]. As goals, structures, and people shift, it becomes difficult to monitor performance and make corrections as in normal times. Therefore, it is vital to map a transitional control structure so that the routine functioning of work is not disturbed.

- Power and political structure: Any organization is a political system made up of different individuals, groups, and coalitions competing for power. Political behavior is thus a natural and expected feature of organizations [12:198]. During the change process, however, these dynamics become even more intense as the old order is dismantled and a new order emerges. This happens because any significant change poses the possibility of upsetting or modifying the balance of power among various stakeholders [15:401]. The uncertainty created by change creates ambiguity, which in turn tends to increase the probability of political activity [12:198]. As said earlier, individuals and groups in the organization tend to take actions and influence the process based on their perception of how the change will affect their relative power positions in the organization. Finally, individuals and groups may engage in political action because of their ideological position on the change - it may be inconsistent with their shared values, culture, or image of the organization.

It follows, then, that an effective organizational change requires mutual trust between the management and the employees that the actions the executives are taking will benefit the employees as well as the organization. Also, as there are so many variables that interact in a change process, sufficient time needs to elapse before the change gets momentum and people get involved. The needed time frame will vary depending on the characteristics of the organization and its people, type of change, and the relative impacts of the change on different groups and individuals.

According to our proposed integrated model, the change process will end up with an equilibrium state. This equilibrium state, however, may not be the desired objective sought by the management. Hence, the management needs to provoke enough tensions 
repeatedly until the desired equilibrium state is achieved. Changing an organization logo, for example, may take a few weeks to be adopted by the people, whereas an incentive plan may take months or years before it gets roots and its outcomes can be realized.

Finally, it should be noted here that selection of a suitable tactic for implementing a change will depend on the nature and types of the sought change, the organization, the general style of management, and the people. The model mandates peoples' involvement, but not necessarily their participation, in the change process. The nature of organizations vary on a continuum of autocracy to democracy by virtue of their missions, structures, cultures, and technologies. Military organizations, for example, are marked by strict submission, clear lines of communication, and tight discipline. Whereas, on the other extreme, some organizations, e.g., universities, are characterized by democracy, lax communication and discipline, and participative management style.

\section{Conclusions}

Practicing executives need to understand the change process in its true perspective if they are going to maintain enduring organizations in the ever changing business environment. Chances are that the plans, programs, and structures that are effective today will not be workable in the years ahead. An overview was provided of some major models which help in understanding, designing, planning, and implementing change. The Systems Model of Change provides a useful basic synthesis for understanding the change. However, it lacks some important factors which contribute to shaping the final outlook of a change. Most significantly so if it directly relates to and/or affects one of those factors. This fact was identified and the Systems Model was improved to account for organizational climate, rewards system, power and political structures, and individual psychological and behavioral characteristics of the organization members, as strong molders of a planned organizational change. With additional considerations in planning a change, these elements can exert their influences during a change process, and can shape the final outcomes of a change process.

\section{Acknowledgments}

The authors thank the referees for their many helpful comments on previous versions of this paper, and acknowledge the support extended by the Research Institute, King Fahd University of Petroleum and Minerals, Dhahran, Saudi Arabia, to allow them to accomplish this research.

\section{References}

Davis, Eileen, “What's On American Managers' Minds?", Management Review, Vol. 84, No. 4, April 1995, pp. 14-20.

Dawson, Patrick, Organizational Change: A Processual Approach, London: Paul Chapman Publishing Company, 1994.

Dunphy, D., and D. Stace, Under New Management: Australian Organizations In Transition, Sydney: McGraw-Hill, 1990.

Goldberg, Beverley, "Manage Change-Not The Chaos Created By Change", Management Review, Vol. 81, No. 11, November 1992, pp. 39-45. 
Hardy, Cynthya, and Franca Redivo, "Power And Organizational Development: A Framework For Organizational Change", Journal of General Management, Vol. 20, No. 2, Winter 1994, pp. $29-41$.

Kahn, William A., "Organizational Change and The Provision of a Secure Base: Lessons From The Field", Human Relations, Vol. 48, No. 5, May 1995, pp. 489-514.

Kaufman, Robert S., "Why Operations Improvement Programs Fail: Four Managerial Contradictions", Sloan Management Review, Vol. 34, No. 1, Fall 1992, pp. 83-93.

Kotter, J. P., and L. A. Schlesinger, "Choosing Strategies For Change", Harvard Business Review, Vol. 57, No. 2, March-April 1979, pp. 106-114.

Lewin, Kurt, Group Decision And Social Change, In G. E. Swanson, T. M. Newcomb, and E. L. Hartley (eds.) "Readings In Social Psychology”, New York: Holt, Rinehart and Winston, 1952.

Lippit, G., "Organization Renewal”, New Jersey: Prentice-Hall, Englewood Cliffs, NJ, 1982.

Miles, Raymond E., Henry J. Coleman, Jr., and W. E. Douglas Creed, "Keys To Success In Corporate Redesign”, California Management Review, Vol. 37, No. 3, Spring 1995, pp. 128-145.

Nadler, David A., "Managing Organizational Change: An Integrative Perspective", The Journal Of Applied Behavioral Science, Vol. 17, No. 2, 1981, pp. 191-211.

Nutt, Paul C., "Tactics Of Implementation”, Academy Of Management Journal, Vol. 29, No. 2, June 1986, pp. 230-261.

Quinn, James Brian, "Managing Strategic Change”, Sloan Management Review, Vol. 22, No. 4, Summer 1980, pp. 3-18.

Quinn, Robert E., "Toward a Theory of Changing: A Means-Ends Model Of The Organizational Improvement Process", Human Relations, Vol. 31, No. 5, May 1978, pp. 395-416.

Rashford, Nicholas S., and David Coghlan, "Phases And Levels Of Organizational Change", Journal Of Managerial Psychology, Vol. 4, No. 3, 1989, pp. 17-21.

Recardo, Ronald J., "Overcoming Resistance To Change", National Productivity Review, Vol 14, No. 1, Spring 1995, pp. 5-12.

Roberts, Karlene H., and Davis M. Hunt, "Organizational Behavior”, Boston: PWS-Kent Publishing Company, 1991.

Sadler, Philip, "Designing Organizations: The Foundation For Excellence", London: Kogan Page Ltd., 1994.

Schiemann, William A., "Organizational Change: Lessons From A Turnaround", Management Review, Vol. 81, No. 4, April 1992, pp. 34-37.

Strebel, Paul, "Choosing The Right Change Path", California Management Review, Vol. 36, No. 2, Winter 1994, pp. 29-51.

Student, Kurt R., "Managing Change: A Psychologist's Perspective", Business Horizons, Vol 21, No. 6, December 1978, pp. 28-33. 
نموذج تكاملي لإدارة التغيير المؤسسي

$$
\begin{aligned}
& \text { خالد أحد بوبشيت، محمد عاصم برلي و افتخار علي نديم } \\
& \text { أساتذة مشاركون محمد عاصني } \\
& \text { قسم المحاسبة ونظم المعلومات الإدارية } \\
& \text { جامعة الملك فها للبترول والمعادن } \\
& \text { الظهران - المملكة العربية السعودية }
\end{aligned}
$$

المستخلص : إن التغيرات في المؤسسات - سواء المخططة أو غير المخططة - تستجيب لقوى

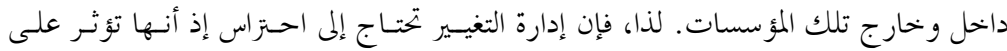

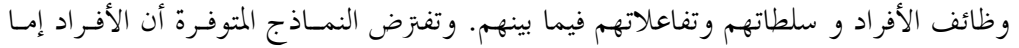

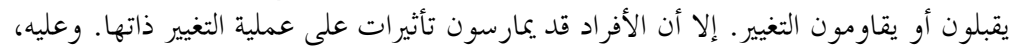

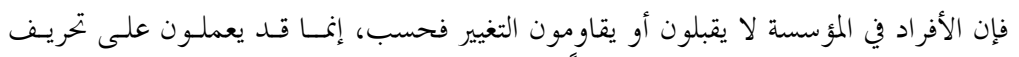

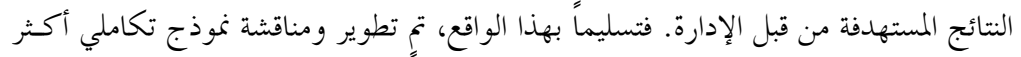

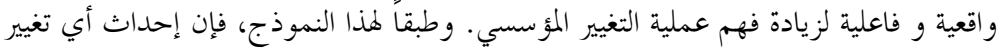

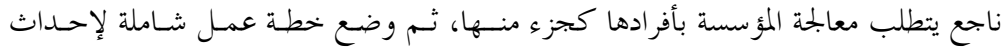

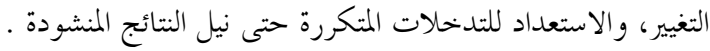

